\title{
Association between adiponectin and heart failure risk in the Physicians' Health Study
}

\author{
Luc Djousséa,b, Jemma B. Wilk ${ }^{a}$, Naomi Q. Hanson ${ }^{c}$, Robert Glynn ${ }^{a}$, Michael Y. Tsai ${ }^{c}$, and \\ J. Michael Gaziano ${ }^{a, b}$ \\ aDepartment of Medicine, Brigham and Women's Hospital and Harvard Medical School, Boston, \\ MA \\ ${ }^{b}$ the Massachusetts Veterans Epidemiology and Research Information Center (MAVERIC) and \\ Geriatric Research (GRECC), Boston Veterans Affairs Healthcare System, Boston, MA \\ 'The Department of Laboratory Medicine \& Pathology, University of Minnesota
}

\begin{abstract}
Limited data are available on the association between adiponectin and incident heart failure. In the current ancillary study to the Physicians' Health Study, we used a prospective nested-case control design to examine whether plasma adiponectin concentration was related to the risk of heart failure. We selected 787 incident heart failure cases and 787 matched controls for the current analysis. Each control was selected using a risk set sampling technique at the time of the occurrence of the index case and matched on year of birth, age at blood collection, and race. Adiponectin was measured using ELISA. Heart failure occurrence was self-reported in annual follow-up questionnaire. Validation of self-reported heart failure in this cohort has been published. The mean age was 58.7 years. In a conditional logistic regression adjusting for age, race, time of blood collection, year of birth, hypertension, atrial fibrillation, smoking, alcohol intake, and exercise, estimates of the relative risk (95\% confidence interval) were 1.0 (ref), 0.74 (0.53-1.04), $0.67(0.48-0.94), 0.70(0.50-0.99)$, and $0.92(0.65-1.30)$ from the lowest to the highest quintile of adiponectin, respectively, $\mathrm{p}$ for quadratic trend 0.004 . Additional adjustment for potential mediating factors including diabetes, C-reactive protein, and body mass index led to the attenuation of the estimate of effect [1.0 (ref), 0.81 (0.57-1.15), 0.75 (0.53-1.06), 0.83 (0.58$1.18)$, and $1.26(0.87-1.81)$ across consecutive quintiles of adiponectin]. Our data are consistent with a J-shaped association between total adiponectin and the risk of heart failure among US male physicians.
\end{abstract}

\footnotetext{
Users may view, print, copy, and download text and data-mine the content in such documents, for the purposes of academic research, subject always to the full Conditions of use:http://www.nature.com/authors/editorial_policies/license.html\#terms

Correspondence: Luc Djoussé, MD, MPH, ScD, FAHA Division of Aging, Brigham and Women's Hospital 1620 Tremont St, $3^{\text {rd }}$ floor; Boston MA 02120 Tel. (617) 525-7591, Fax. (617) 525-7739, ldjousse@ rics.bwh.harvard.edu.

Author contribution: Study design (LD); Statistical analysis (LD, JBW); drafting the manuscript (LD); Heart failure adjudication (LD and staff); laboratory assays (MT, NH); critical review of the manuscript (LD, NQH, MYT, JBW, RG, JMG); Obtaining funding for this study (LD).

Disclosures: None
} 


\section{Keywords}

Adiponectin; epidemiology; heart failure; risk factors

Heart failure (HF) remains an important public health issue(1;2) and is associated with a high mortality(3) despite improved medical and surgical management of HF. A large proportion of HF cases is accounted for by antecedent coronary heart disease (CHD) and hypertension,(4-6) suggesting that predictors of CHD and hypertension might influence the risk of HF. Adiposity is positively associated with HF risk(7;8) as well as its major risk factors (diabetes(9), hypertension, and coronary artery disease(10-12)). Adipocytes express several active hormones (including adiponectin) that influence cardiometabolic factors $(13 ; 14)$ and subsequent risk of diabetes and CHD. Previous data have reported an inverse association between measures of adiposity and plasma levels of adiponectin as well as favorable effects of higher adiponectin levels on the risk of type 2 diabetes(15-17). In a mouse model of myocardial infarction, adiponectin-knockout mice showed exacerbation of left ventricular dilation, myocyte hypertrophy, and contractile dysfunction compared with wild-type mice, 4 weeks after ligation of left anterior descending artery(18). In contrast, administration of adiponectin to wild-type mice led to decreased left ventricular dilation and interstitial fibrosis, improved left ventricular function, and diminished apoptosis(18). Other experiments showed that adiponectin inhibits cardiac hypertrophic response to alphaadrenergic receptor stimulation(19). These data suggest that adiponectin may play a role in the development of HF. However, limited studies have tested such a hypothesis in a community setting among humans. Results from two previous prospective studies from Framingham and Sweden showed no statistically significant association between plasma adiponectin and incident HF. Whether these reported null findings from the above studies were due to limited statistical power in each study or absence of a causal association between adiponectin and HF risk remains unclear. Therefore, the current project sought to assess the association between total plasma adiponectin and incident $\mathrm{HF}$ in a prospective nested case-control study of US male physicians.

\section{Methods}

\section{Study population}

This is an ancillary study of the Physicians' Health Study I, which is a completed randomized, double blind, placebo-controlled trial designed to study low-dose aspirin and beta-carotene for the primary prevention of cardiovascular disease and cancer. A detailed description of the PHS I has been published.(20) Current analyses used a prospective nested case-control design to select subjects. Specifically, we limited our selection on PHS I participants that provided blood samples between 1997 and 2001. For each case of HF, we randomly selected a control among participants who were alive and free of HF at the time of diagnosis of the index case and matched to the case on age at blood collection (within 2 years), race, year of birth (same), and time of blood collection (within 90 days). We have a final sample of 822 pairs. Due to missing data on adiponectin on 35 subjects, current analyses are based on 787 pairs. Each participant signed an informed consent and the Institutional review Board at Brigham and Women's Hospital approved the study protocol. 


\section{Measurement of adiponectin}

Adiponectin was measured using the Human Adiponectin Quantikine ELISA ( R \& D Systems, Minneapolis, MN) at the University of Minnesota, Minneapolis, MN. The interassay coefficient of variation was $5.5 \%$.

\section{Ascertainment of incident HF in the PHS}

The ascertainment of endpoints including HF in the PHS has been achieved using yearly follow-up questionnaires (except during the first year when each participant completed two questionnaires six months apart) to obtain information on compliance with the intervention and the occurrence of new outcomes including HF. Despite initial self-report of HF in this cohort, we previously validated HF diagnosis in the PHS using the Framingham criteria(21) on supplemental questionnaires in a subsample(22) as well as via chart review on limited number of $\mathrm{HF}(23)$. Using these criteria, the positive predictive value of self-reported HF was $91 \%$ with excellent agreement between the 2 reviewers (kappa=92\%).

\section{Other variables}

Demographic information was obtained through self-reports. At baseline, each subject provided information on exercise [how often do you exercise vigorously enough to work up sweat? Possible answers included rarely/never, 1-3/month, 1/week, 2-4/week, 5-6/week, and daily]; smoking (never, former, and current smoker); and alcohol intake (rarely/never, 1-3 per month, 1 per week, 2-4/week, 5-5/week, daily, and 2+/day). Self-reported baseline weight and height were used to compute body mass index (weight in kilograms divided by height in meter squared). Data on comorbidity including hypertension, atrial fibrillation, hyperlipidemia, and diabetes was collected at baseline and through follow-up questionnaires.

\section{Statistical analyses}

We created quintiles of adiponectin using the distribution of adiponectin in the control series. Means and percentages of baseline characteristics of the study participants are presented according to quintiles of adiponectin. We used conditional logistic regression to estimate the relative risk of HF using the lowest quintile of adiponectin as reference category. The initial model adjusted for matching variables only (race, age, time of blood collection, and year of birth). The final model additionally controlled for hypertension, atrial fibrillation, cigarette smoking, alcohol consumption, and exercise. Missing data in some of the covariates resulted in a loss of 26 matching pairs in the multivariable model. To obtain a $\mathrm{p}$ value for linear trend, we created a new variable that was assigned the median value of adiponectin in each quintile within the control series and fitted such a variable in the conditional logistic regression. Similarly, to obtain $\mathrm{p}$ value for quadratic trend, we added a squared term of the new variable in the above model. We assessed confounding using a $10 \%$ estimate change. Lastly, we examined potential mediation by body mass index, diabetes, and C-reactive protein by assessing whether their inclusion in the multivariable model would lead to the attenuation of the relative risk. All analyses were performed using SAS (SAS version $9.1, \mathrm{NC}$ ) and the alpha level was set at 0.05 . All $\mathrm{p}$ values were 2 -sided. 


\section{Results}

Mean age among 1574 participants included in these analyses was 58.7 years (range 39.8 to 82.5 ) and median adiponectin was $7.41 \mu \mathrm{g} / \mathrm{ml}$ (interquartile range 4.39 to 9.51 ). Baseline characteristics according to the quintiles of total adiponectin are presented in Table 1. Higher concentration of adiponectin was associated with older age, lower body mass index, higher prevalence of alcohol consumption and physical activity, and lower prevalence of diabetes, current smoking, and hypertension. In a conditional logistic regression, there was evidence for an inverse association between total adiponectin and risk of heart failure. From the lowest to the highest quintiles of adiponectin, relative risk for heart failure were 1.0 (ref), 0.74 (0.53-1.04), 0.67 (0.48-0.94), 0.70 (0.50-0.99), and 0.92 (0.65-1.30), respectively, adjusting for matching factors, hypertension, atrial fibrillation, cigarette smoking, alcohol consumption, and physical activity (Table 2). As expected, additional adjustment for potential intermediate factors (body mass index, diabetes, hsCRP) attenuated the relative risks (1.0 (ref), 0.81 (0.57-1.15), 0.75 (0.53-1.06), and 0.83 (0.58-1.18), and 1.26 (0.871.81) across consecutive quintiles of total adiponectin).

\section{Discussion}

In this prospective nested case-control study of apparently healthy male physicians, we observed that after adjustment for potential confounding factors, total adiponectin was inversely associated with heart failure risk in a non-linear fashion with the lowest risk observed in the third quintile of total adiponectin.

While adiponectin has been inversely associated with $\operatorname{CHD}(24)$, adiponectin in patients with established HF has been shown to predict higher mortality $(25 ; 26)$. However, few studies have examined whether serum adiponection is associated with incident HF in community settings. In a prospective study of 946 male subjects (70-year old), total adiponectin was not associated with a statistically significant association with incident HF after an average follow up of 9 years (crude HR=0.90 (95\% CI: 0.72-1.13) per standard deviation of adiponectin](27). These results are contrary to our findings of suggestive J-shaped association of adiponectin to HF. The fact that Ingelsson et al(27) fitted adiponectin as a linear term might have prevented the authors to observe a non-linear relationship. In addition, it is reasonable to argue that myocardial infarction and insulin sensitivity could be potential intermediate factors between adiponectin and HF; hence, adjustment for those factors would attenuate any true relationship. Indeed, adjustment for body mass index, diabetes, myocardial infarction, and hypertension completely eliminated the non-significant association (HR: 1.09 (0.86-1.38) in the paper by Ingelsson and colleagues(27). Lastly, with only 76 events, the authors lacked statistical power to detect a modest effect of adiponectin on HF. Data from the Framingham Offspring study(28) ( $n=2739)$ reported 58 incident HF after six years of follow up with age and sex adjusted hazard ratios of 1.0 (ref), 0.84 (0.451.57), and $0.64(0.32-1.27)$ across consecutive categories of adiponectin. In the Framingham study(28), the wide confidence intervals around the point estimates suggest lack of precision and point at low statistical power to detect any modest effect of adiponection on HF risk. 
What biologic mechanisms could support a beneficial effect of adiponectin on the development of HF? Elevated adiponectin levels have been shown to improve nitric oxide production, reduce inflammation, apoptosis, improve insulin sensitivity, and left ventricular systolic function(29). In animal experiments, hypoadiponectinemia in hypertension-induced diastolic HF exacerbates left ventricular hypertrophy, diastolic dysfunction, and diastolic $\mathrm{HF}(30)$. In addition, several studies have reported an inverse relation between adiponectin and major risk factors of HF including adiposity(31), diabetes(31;32), myocardial infarction(24), and hypertension(33;34). Could elevated concentrations of adiponectin carry health risk? A U-shaped association between adiponectin and total mortality has been reported(35). Furthermore, a non-linear relation between total and high-molecular weight adiponectin with incident diabetes (a major risk factor for HF) was reported in older adults(36). These data suggest that while moderate levels of adiponectin may be beneficial for cardiovascular risk, it is possible that extremely higher concentrations of adiponectin could be a direct response to homeostatic disregulation (i.e., underlying insulin resistance) or inflammation. Such a hypothesis would be consistent with J- or U-shape association between adiponectin and HF, diabetes, or mortality. At this point, we are unable to test such a hypothesis and are relying on future studies for further elucidation.

\section{Study strengths and limitations}

The large number of participants, $22+$ years of follow up, and the standardized methods of endpoints ascertainment and measurement of adiponectin are major strengths of this study. In addition, we were able to minimize confounding by age, race, time of blood collection, and birth cohort effect through matching between each case and its corresponding control. On the other hand, the fact that all participants were male physicians, most of whom were Caucasians, limits the generalizabilty of the current findings. Furthermore, we did not have data on etiology or left ventricular systolic function to further subclassify HF. In the current study, HF diagnosis was self-reported by participants; despite a $91 \%$ positive predictive value of self-reported HF against validation via medical record review in a subsample and the fact that participants were physicians, it is possible that self-report of HF may have led to misclassification of HF. Such misclassification is more likely to be non-differential with respect to adiponectin concentration and would likely have led to an underestimation of the true effect. We did not have data on HF etiology and were not able to separate HF with normal versus poor left ventricular ejection fraction. Lastly, this ancillary study could not support the cost of biomarker measurement on all PHS I subjects. However, the fact that we randomly selected control subjects using a risk set technique makes the findings generalizable to the entire PHS I population.

In conclusion, our data showed a J-shaped association between total plasma adiponectin and incident HF among US male physicians. Confirmation of these data in other populations is warranted.

\section{Acknowledgement}

We are indebted to the participants in the PHS for their outstanding commitment and cooperation and to the entire PHS staff for their expert and unfailing assistance. 
Funding/Support: This project was supported by R01HL92946-02 from the NHLBI and supplement HL92946S1 from the Office of Dietary Supplement (Dr. Djousse). The Physicians' Health Study is supported by grants CA-34944 and CA-40360, and CA-097193 from the National Cancer Institute and grants HL-26490 and HL-34595 from the National Heart, Lung, and Blood Institute, Bethesda, MD.

\section{References}

1. Rosamond W, Flegal K, Furie K, Go A, Greenlund K, Haase N, et al. Heart disease and stroke statistics--2008 update: a report from the American Heart Association Statistics Committee and Stroke Statistics Subcommittee. Circulation. 2008; 117:e25-146. [PubMed: 18086926]

2. Jessup M, Brozena S. Heart failure. N Engl J Med. 2003; 348:2007-18. [PubMed: 12748317]

3. Senni M, Tribouilloy CM, Rodeheffer RJ, Jacobsen SJ, Evans JM, Bailey KR, Redfield MM. Congestive heart failure in the community: a study of all incident cases in Olmsted County, Minnesota, in 1991. Circulation. 1998; 98:2282-9. [PubMed: 9826315]

4. Gheorghiade M, Bonow RO. Chronic heart failure in the United States: a manifestation of coronary artery disease. Circulation. 1998; 97:282-9. [PubMed: 9462531]

5. Gottdiener JS, Arnold AM, Aurigemma GP, Polak JF, Tracy RP, Kitzman DW, et al. Predictors of congestive heart failure in the elderly: the Cardiovascular Health Study. J Am Coll Cardiol. 2000; 35:1628-37. [PubMed: 10807470]

6. Hunt SA, Baker DW, Chin MH, Cinquegrani MP, Feldman AM, Francis GS, et al. ACC/AHA guidelines for the evaluation and management of chronic heart failure in the adult: executive summary. A report of the American College of Cardiology/American Heart Association Task Force on Practice Guidelines (Committee to revise the 1995 Guidelines for the Evaluation and Management of Heart Failure). J Am Coll Cardiol. 2001; 38:2101-13. [PubMed: 11738322]

7. Kenchaiah S, Evans JC, Levy D, Wilson PW, Benjamin EJ, Larson MG, et al. Obesity and the risk of heart failure. N Engl J Med. 2002; 347:305-13. [PubMed: 12151467]

8. Kenchaiah S, Sesso HD, Gaziano JM. Body mass index and vigorous physical activity and the risk of heart failure among men. Circulation. 2009; 119:44-52. [PubMed: 19103991]

9. Biggs ML, Mukamal KJ, Luchsinger JA, Ix JH, Carnethon MR, Newman AB, et al. Association between adiposity in midlife and older age and risk of diabetes in older adults. JAMA. 2010; 303:2504-12. [PubMed: 20571017]

10. Laughlin GA, Barrett-Connor E, May S, Langenberg C. Association of adiponectin with coronary heart disease and mortality: the Rancho Bernardo study. Am J Epidemiol. 2007; 165:164-74. [PubMed: 17101706]

11. Schulze MB, Shai I, Rimm EB, Li T, Rifai N, Hu FB. Adiponectin and future coronary heart disease events among men with type 2 diabetes. Diabetes. 2005; 54:534-9. [PubMed: 15677512]

12. Rothenbacher D, Brenner H, Marz W, Koenig W. Adiponectin, risk of coronary heart disease and correlations with cardiovascular risk markers. Eur Heart J. 2005; 26:1640-6. [PubMed: 15932907]

13. von Eynatten M, Hamann A, Twardella D, Nawroth PP, Brenner H, Rothenbacher D. Relationship of adiponectin with markers of systemic inflammation, atherogenic dyslipidemia, and heart failure in patients with coronary heart disease. Clin Chem. 2006; 52:853-9. [PubMed: 16556684]

14. Wannamethee SG, Tchernova J, Whincup P, Lowe GD, Rumley A, Brown K, et al. Associations of adiponectin with metabolic and vascular risk parameters in the British Regional Heart Study reveal stronger links to insulin resistance-related than to coronory heart disease risk-related parameters. Int J Obes (Lond). 2007; 31:1089-98. [PubMed: 17264850]

15. Snehalatha C, Mukesh B, Simon M, Viswanathan V, Haffner SM, Ramachandran A. Plasma adiponectin is an independent predictor of type 2 diabetes in Asian indians. Diabetes Care. 2003; 26:3226-9. [PubMed: 14633806]

16. Choi KM, Lee J, Lee KW, Seo JA, Oh JH, Kim SG, et al. Serum adiponectin concentrations predict the developments of type 2 diabetes and the metabolic syndrome in elderly Koreans. Clin Endocrinol (Oxf). 2004; 61:75-80. [PubMed: 15212647]

17. Yamamoto Y, Hirose H, Saito I, Nishikai K, Saruta T. Adiponectin, an adipocyte-derived protein, predicts future insulin resistance: two-year follow-up study in Japanese population. J Clin Endocrinol Metab. 2004; 89:87-90. [PubMed: 14715832] 
18. Shibata R, Izumiya Y, Sato K, Papanicolaou K, Kihara S, Colucci WS, et al. Adiponectin protects against the development of systolic dysfunction following myocardial infarction. J Mol Cell Cardiol. 2007; 42:1065-74. [PubMed: 17499764]

19. Shibata R, Ouchi N, Ito M, Kihara S, Shiojima I, Pimentel DR, et al. Adiponectin-mediated modulation of hypertrophic signals in the heart. Nat Med. 2004; 10:1384-9. [PubMed: 15558058]

20. Final report on the aspirin component of the ongoing Physicians' Health Study. Steering Committee of the Physicians' Health Study Research Group. N Engl J Med. 1989; 321:129-35. [PubMed: 2664509]

21. Ho KK, Anderson KM, Kannel WB, Grossman W, Levy D. Survival after the onset of congestive heart failure in Framingham Heart Study subjects. Circulation. 1993; 88:107-15. [PubMed: 8319323]

22. Djousse L, Gaziano JM. Alcohol consumption and risk of heart failure in the Physicians' Health Study I. Circulation. 2007; 115:34-9. [PubMed: 17130341]

23. Djousse L, Driver JA, Gaziano JM. Relation between modifiable lifestyle factors and lifetime risk of heart failure. JAMA. 2009; 302:394-400. [PubMed: 19622818]

24. Pischon T, Girman CJ, Hotamisligil GS, Rifai N, Hu FB, Rimm EB. Plasma adiponectin levels and risk of myocardial infarction in men. JAMA. 2004; 291:1730-7. [PubMed: 15082700]

25. Tsutamoto T, Tanaka T, Sakai H, Ishikawa C, Fujii M, Yamamoto T, Horie M. Total and high molecular weight adiponectin, haemodynamics, and mortality in patients with chronic heart failure. Eur Heart J. 2007; 28:1723-30. [PubMed: 17507366]

26. George J, Patal S, Wexler D, Sharabi Y, Peleg E, Kamari Y, et al. Circulating adiponectin concentrations in patients with congestive heart failure. Heart. 2006; 92:1420-4. [PubMed: 16621874]

27. Ingelsson E, Riserus U, Berne C, Frystyk J, Flyvbjerg A, Axelsson T, et al. Adiponectin and risk of congestive heart failure. JAMA. 2006; 295:1772-4. [PubMed: 16622137]

28. Frankel DS, Vasan RS, D'Agostino RB Sr. Benjamin EJ, Levy D, Wang TJ, Meigs JB. Resistin, adiponectin, and risk of heart failure the framingham offspring study. J Am Coll Cardiol. 2009; 53:754-62. [PubMed: 19245965]

29. Okamoto H. Can adiponectin be a novel metabolic biomarker for heart failure? Circ J. 2009; 73:1012-3. [PubMed: 19465781]

30. Sam F, Duhaney TA, Sato K, Wilson RM, Ohashi K, Sono-Romanelli S, et al. Adiponectin deficiency, diastolic dysfunction, and diastolic heart failure. Endocrinology. 2010; 151:322-31. [PubMed: 19850745]

31. Weyer C, Funahashi T, Tanaka S, Hotta K, Matsuzawa Y, Pratley RE, Tataranni PA. Hypoadiponectinemia in obesity and type 2 diabetes: close association with insulin resistance and hyperinsulinemia. J Clin Endocrinol Metab. 2001; 86:1930-5. [PubMed: 11344187]

32. Daimon M, Oizumi T, Saitoh T, Kameda W, Hirata A, Yamaguchi H, et al. Decreased serum levels of adiponectin are a risk factor for the progression to type 2 diabetes in the Japanese Population: the Funagata study. Diabetes Care. 2003; 26:2015-20. [PubMed: 12832305]

33. Chow WS, Cheung BM, Tso AW, Xu A, Wat NM, Fong CH, et al. Hypoadiponectinemia as a predictor for the development of hypertension: a 5-year prospective study. Hypertension. 2007; 49:1455-61. [PubMed: 17452504]

34. Iwashima Y, Katsuya T, Ishikawa K, Ouchi N, Ohishi M, Sugimoto K, et al. Hypoadiponectinemia is an independent risk factor for hypertension. Hypertension. 2004; 43:1318-23. [PubMed: 15123570]

35. Kizer JR, Arnold AM, Jenny NS, Cushman M, Strotmeyer ES, Ives DG, et al. Longitudinal changes in adiponectin and inflammatory markers and relation to survival in the oldest old: the Cardiovascular Health Study All Stars study. J Gerontol A Biol Sci Med Sci. 2011; 66:1100-7. [PubMed: 21659339]

36. Kizer JR, Arnold AM, Benkeser D, Ix JH, Djousse L, Zieman SJ, et al. Total and high-molecularweight adiponectin and risk of incident diabetes in older people. Diabetes Care. 2012; 35:415-23. [PubMed: 22148099] 


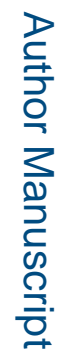

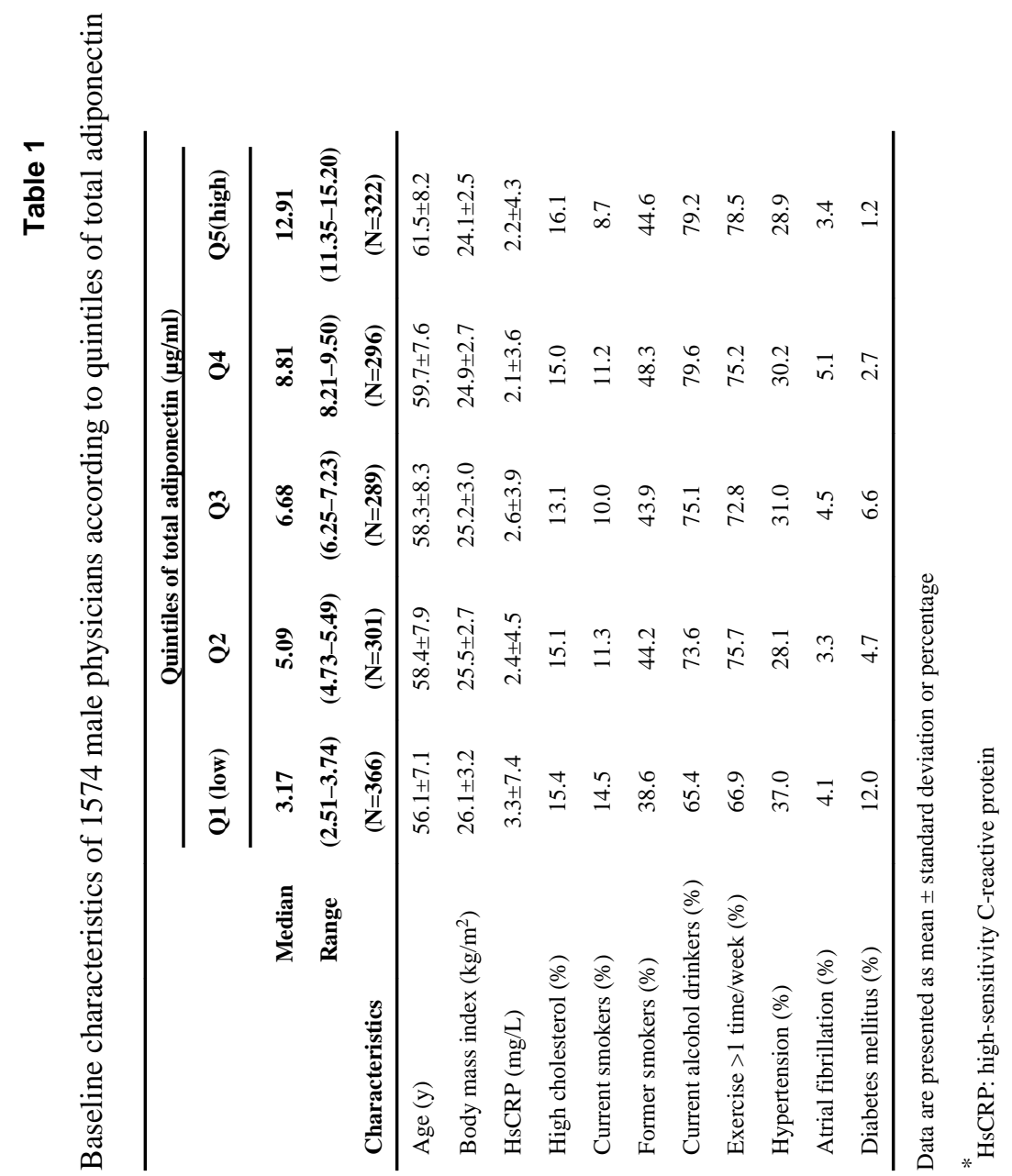

Obesity (Silver Spring). Author manuscript; available in PMC 2013 October 15. 


\section{Table 2}

Relative risk (95\% CI) of heart failure according to quintiles of total adiponectin

\begin{tabular}{|c|c|c|c|c|}
\hline \multirow{2}{*}{\multicolumn{2}{|c|}{$\begin{array}{l}\text { Quintiles of total adiponectin: } \\
\text { Median (range) in } \mu \mathrm{g} / \mathrm{ml}\end{array}$}} & \multirow{3}{*}{$\frac{\text { Cases }}{209}$} & \multicolumn{2}{|c|}{ Relative risk (95\% CI) } \\
\hline & & & \multirow{2}{*}{$\frac{\text { Model 1 }^{*}}{1.00}$} & \multirow{2}{*}{$\frac{\text { Model } \mathbf{2}^{\dagger}}{1.00}$} \\
\hline Q1(low) & $3.17(2.51-3.74)$ & & & \\
\hline Q2 & $5.09(4.73-5.49)$ & 143 & $0.67(0.49-0.92)$ & $0.74(0.53-1.04)$ \\
\hline Q3 & $6.68(6.25-7.23)$ & 131 & $0.61(0.45-0.84)$ & $0.67(0.48-0.94)$ \\
\hline Q4 & $8.81(8.21-9.50)$ & 140 & $0.65(0.47-0.90)$ & $0.70(0.50-0.99)$ \\
\hline Q5 (high) & $12.91(11.35-15.20)$ & 164 & $0.75(0.54-1.03)$ & $0.92(0.65-1.30)$ \\
\hline \multicolumn{2}{|c|}{$\mathrm{P}$ for quadratic trend } & & 0.003 & 0.004 \\
\hline
\end{tabular}

Model 1 adjusted for matching factors (age, race, time of blood collection, and year of birth)

${ }^{\dagger}$ Conditional logistic regression with additional adjustment for hypertension, atrial fibrillation, cigarette smoking, alcohol, and exercise (there was a loss of 26 pairs due to missing covariates in Model 2). 